\title{
Friedel-Crafts acylation of 2-methoxynaphthalene with acetic anhydride catalyzed by phosphotungstic acid in ionic liquid
}

\author{
Y. Guo, J. Sun, F. Guo, Yu. He, P. Chen* \\ School of Chemistry and Materials Science, Liaoning Shihua University, Dandong Road 1, Fushun 113001, China
}

Received, November 12, 2016; Revised, February 23, 2018

The Friedel-Crafts acylation of 2-methoxynaphthalene (2-MN) with acetic anhydride (AA) was carried out in the ionic liquid (IL) butylpyridinium tetrafluoroborate $\left([\mathrm{BPy}] \mathrm{BF}_{4}\right)$ using phosphotungstic acid $\left(\mathrm{H}_{3} \mathrm{PW}_{12} \mathrm{O}_{40}\right)$ as the catalyst. The $\left[\mathrm{BPy}_{\mathrm{BF}}\right.$-mediated 2-MN acylation displays good conversion and selectivity towards 1-acyl-2methoxynaphthalene (1-AC-2-MN), with 70.4\% conversion of 2-MN and $96.4 \%$ selectivity to $1-\mathrm{AC}-2-\mathrm{MN}$ obtained under the optimal conditions. Owing to the rearrangement of 1-AC-2-MN, 6-acyl-2-methoxynaphthalene (6-AC-2-MN) can be detected after $1 \mathrm{~h}$ of reaction time, with the highest $6-\mathrm{AC}-2-\mathrm{MN}$ yield of $11.3 \%$ obtained under the examined reaction conditions. The system can be recycled and reused at least 6 times without significant loss of activity, indicating the good stability of the $\mathrm{H}_{3} \mathrm{PW}_{12} \mathrm{O}_{40} /[\mathrm{BPy}] \mathrm{BF}_{4}$ catalytic system.

Keywords: Friedel-Crafts acylation, Ionic liquid, Heteropolyacid, 2-Methoxynaphthalene

\section{INTRODUCTION}

Aromatic ketones are important intermediates in fine chemical, pharmaceutical and agrochemical industrial processes [1,2]. Friedel-Crafts acylation is one of the most effective methods for preparing aromatic ketones. A typical example is the acylation of 2-MN, which produces the important synthetic intermediates 1-AC-2-MN and 6-AC-2$\mathrm{MN}$ [3-5]. Current industrial processes for 2-MN acylation use acyl halides or anhydrides as acylating reagents over stoichiometric amounts of Lewis acids (such as $\mathrm{AlCl}_{3}$ ) or proton acids as catalysts [6]. However, these catalysts generate many problems as they are polluting, corrosive, and the catalysts are not recyclable during the work-up $[7,8]$. Due to the environmental restrictions, replacement of conventional catalytic methods is desirable. An alternative would be the application of heterogeneous catalysts instead of Lewis or proton acid catalysts, since they are more environmentally friendly, recyclable and reusable, and some of them also show good shape-selective properties in the acylation of 2-MN [9-13]. Accordingly, the acylation of 2-MN with various solid catalysts including BEA [9-13], HY [14,15], beta [16-21], MCM-41 [22,23], ITQ-7 [24,25], HMS [26], Nafion/silica composites [27,28], etc., has been extensively studied in the past decades. However, they are in general less active towards 2$\mathrm{MN}$ acylation as compared to Lewis or proton acid catalysts (for example, $\mathrm{AlCl}_{3}$ ).

Heteropolyacids (HPA), being a type of strong acid catalysts, have attracted much attention both in the academic research field and industrial applications in recent years [29,30]. Among the various Keggin type - HPA, the phosphotungstic acid $\mathrm{H}_{3} \mathrm{PW}_{12} \mathrm{O}_{40}$ has been found to be effective towards many organic reactions such as oxidation [31-38], esterification [39-44], Friedel-Crafts alkylation [45-48] and acylation [49-54]. Owing to its high stability and solid precipitation property, it is normally recyclable and reusable in the homogeneous catalytic system, and is also less corrosive as compared to Lewis or proton acids. Despite its excellent catalytic performance has been recognized, the acylation of 2-MN using $\mathrm{H}_{3} \mathrm{PW}_{12} \mathrm{O}_{40}$ as catalyst has not yet been fully examined.

Theoretically, acylation of 2-MN generally occurs at the kinetically controlled 1-position, forming 1-AC-2-MN as the major product. The reaction also has the trend to form another thermodynamically stable 6-position product 6-AC$2-\mathrm{MN}$ with the extension of reaction time at higher temperatures or over shape-selective zeolite catalysts (for example, HBEA [9-13]. Chlorobenzene has been found as a preferable solvent, since it can result in high acylation yield [9-13]. Considering green catalysis, the application of ionic liquids as non-volatile solvents is also attractive. Ionic liquids have many unique chemical and physical properties such as negligible volatility, good thermal stability and excellent solubility of both inorganic and organic compounds in them [55]. Many ionic liquids have been successfully applied as solvents for the Friedel-Crafts acylation reactions [56-63]. Nevertheless, to the best of our knowledge, the acylation of 2-MN using the heteropolyacid $\mathrm{H}_{3} \mathrm{PW}_{12} \mathrm{O}_{40}$ as catalyst and ionic liquid as solvent have never been reported in the literature. In this work, the Friedel-Crafts acylation of 2-MN with acetic anhydride using

\footnotetext{
* To whom all correspondence should be sent. (C) 2019 Bulgarian Academy of Sciences, Union of Chemists in Bulgaria EEmail: chenping-fs@163.com
} 
Y. Guo et al.: Friedel-Crafts acylation of 2-methoxynaphthalene with acetic anhydride catalyzed by phosphotungstic... phosphotungstic acid $\mathrm{H}_{3} \mathrm{PW}_{12} \mathrm{O}_{40}$ as renewable catalyst and the ionic liquid $\left[\mathrm{BP}_{\mathrm{y}}\right] \mathrm{BF}_{4}$ as an efficient and non-volatile solvent is reported as a result of our efforts.

\section{EXPERIMENTAL}

All chemicals were purchased from the Sinopharm Chemical Reagent Co. Ltd (China) or Acros and used without further purification. $\left[\mathrm{BP}_{\mathrm{y}}\right] \mathrm{BF}_{4}$ was synthesized according to the literature procedures [64-66]. ${ }^{1} \mathrm{H}$ NMR spectra were recorded on a Bruker Avance DPX-400 spectrometer. IR spectra were recorded on a Perkin Elmer Frontier FT-IR spectrometer. Gas chromatography (GC) and GC-MS were performed on an Agilent 7890A-5975C instrument equipped with an SE-30 capillary column $(0.25 \mathrm{~mm} \times 30 \mathrm{~m} \times$ $0.10 \mu \mathrm{m})$, a FID and a MS detector.

\section{Typical procedure for Friedel-Crafts acylation of $2-M N$}

$3.16 \mathrm{~g}$ (20 mmol) of 2-MN, $3.06 \mathrm{~g} \mathrm{(30} \mathrm{mmol)} \mathrm{of}$ $\mathrm{AA}$ and $10 \mathrm{~mL}$ of $\left[\mathrm{BP}_{\mathrm{y}}\right] \mathrm{BF}_{4}$ were added into a three-neck round flask. A certain amount of $\mathrm{H}_{3} \mathrm{PW}_{12} \mathrm{O}_{40}$ catalyst was then added to start the reaction. The reaction temperature was gradually increased to $120{ }^{\circ} \mathrm{C}$. After the reaction, the mixture was cooled down to room temperature and extracted with ethyl acetate three times $(3 \times 10 \mathrm{~mL})$. The recycled IL containing the catalyst $\mathrm{H}_{3} \mathrm{PW}_{12} \mathrm{O}_{40}$ was further dried at $80{ }^{\circ} \mathrm{C}$ under vacuum, then used directly for the next catalytic run. The organic layer containing the unreacted substrates and products was then diluted, and subjected to GC analysis. GC analysis was performed under the following conditions: initial temperature: $90{ }^{\circ} \mathrm{C}$ for 1 $\mathrm{min} \rightarrow$ ramp rate: $20{ }^{\circ} \mathrm{C} / \mathrm{min} \rightarrow$ final temperature: $260{ }^{\circ} \mathrm{C}$ for $10 \mathrm{~min}$. Injector/detector temperatures: $260{ }^{\circ} \mathrm{C} / 260{ }^{\circ} \mathrm{C}$. Nitrogen was used as carrier gas. The formation of possible products was confirmed by comparison of the retention time with that of authentic samples. Quantitative data were analyzed using a N 2000 Chemical work station software with the GC instrument. The conversion and yield were calculated from calibration curves $\left(\mathrm{r}^{2}>0.999\right)$ recorded prior to the reaction using naphthalene as the internal standard. The pure product of 1-AC-2$\mathrm{MN}$ was isolated by flash chromatography on silica

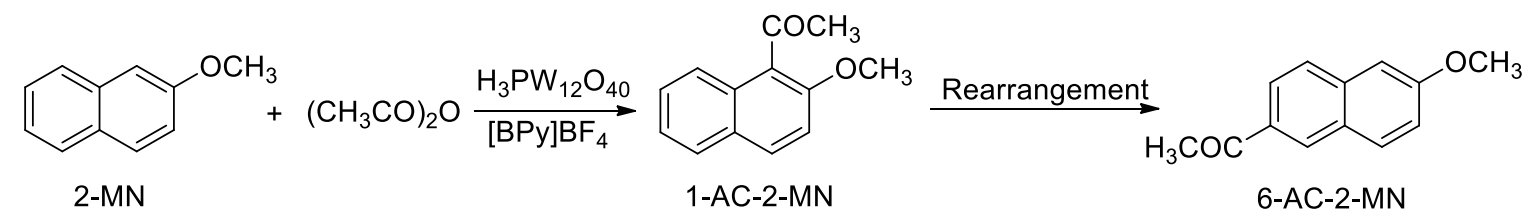

Scheme 1. Friedel-Crafts acylation of 2-MN. 
Y. Guo et al.: Friedel-Crafts acylation of 2-methoxynaphthalene with acetic anhydride catalyzed by phosphotungstic...

The reactions were carried out using different solvents, temperatures, amount of catalyst and molar ratios of the substrates. In general, 1-AC-2$\mathrm{MN}$ is observed as the major product within $1 \mathrm{~h}$ of the reaction according to GC analysis, whereas the thermodynamically stable 6-position acylated product 6-AC-2-MN can be detected after $1 \mathrm{~h}$ at higher temperatures $\left(>100^{\circ} \mathrm{C}\right)$.

\section{Influence of solvents on the acylation of 2-MN}

The reactions were carried out in $\left[\mathrm{BP}_{\mathrm{y}}\right] \mathrm{BF}_{4}$, chlorobenzene and under solvent-free condition. The data on the conversion of 2-MN and selectivity towards 1-AC-2-MN are shown in Figs. 1 and 2. When the ionic liquid $\left[\mathrm{BP}_{\mathrm{y}}\right] \mathrm{BF}_{4}$ is used as solvent, the reaction shows higher conversion than that in chlorobenzene or solvent-free condition (Fig. 1). The conversion of 2-MN gradually increases with the increase in reaction time, and finally reaches about $60.3 \%$ after $6 \mathrm{~h}$ and does not significantly increase afterwards. With respect to the product selectivity, the reactions show the highest 1-AC-2$\mathrm{MN}$ yield at $1 \mathrm{~h}$ in all examined conditions. [BPy $] \mathrm{BF}_{4}$-mediated reaction provides the best selectivity towards 1-AC-2-MN. The selectivity is almost $100 \%$ at $1 \mathrm{~h}$ and above $95 \%$ after $10 \mathrm{~h}$. The decrease in selectivity can be explained by the rearrangement of 1-AC-2-MN to 6-AC-2-MN. In the case of the reactions in chlorobenzene and solventfree condition the selectivities are $93.2 \%$ and $86.5 \%$ after $1 \mathrm{~h}$, and decrease gradually to $87.3 \%$ for chlorobenzene and $80.6 \%$ for solvent-free condition after $10 \mathrm{~h}$. The calculated yields of 6-AC$2-\mathrm{MN}$ are $3.1 \%$ in $[\mathrm{BPy}] \mathrm{BF}_{4}, 5.5 \%$ in chlorobenzene and $8.6 \%$ for solvent free conditions after $10 \mathrm{~h}$.

\section{Influence of temperature on the acylation of 2-MN}

Table 1 exhibits the data for the acylation of 2$\mathrm{MN}$ in the presence of $\left[\mathrm{BP}_{\mathrm{y}}\right] \mathrm{BF}_{4}$ at different temperatures. It can be observed that the reaction temperature significantly affects the conversion of 2-MN. The conversion of 2-MN increased rapidly with the temperature increase. All examined reactions show nearly $100 \%$ selectivity towards 1 AC-2-MN below $100^{\circ} \mathrm{C}$. The highest conversion of $2-\mathrm{MN}(66.1 \%)$ is achieved at $120{ }^{\circ} \mathrm{C}$ with 1 -AC-2$\mathrm{MN}$ selectivity of $98.3 \%$. Continued increase in the temperature leads to a decrease of 1-AC-2-MN yield but an increase of 6-AC-2-MN yield, which might be due to the acceleration of the isomerization reaction rate with the temperature increase. Accordingly, the selectivity of 1-AC-2$\mathrm{MN}$ is decreased at higher temperatures [9-13]. Nevertheless, the conversion is lower at $140{ }^{\circ} \mathrm{C}$ than that at $120{ }^{\circ} \mathrm{C}$. This might be due to the deacylation of 1-AC-2-MN at a higher temperature $\left(140{ }^{\circ} \mathrm{C}\right)$ during the isomerization process, which has also been frequently reported in the literature [9-28]. Moreover, the reaction solution becomes dark at higher temperatures $\left(>140{ }^{\circ} \mathrm{C}\right)$, which might be due to the decomposition of the ionic liquid $[\mathrm{BPy}] \mathrm{BF}_{4}$ or of the catalyst. The reaction shows $64.7 \%$ of 1-AC-2-MN as the highest yield with $98.3 \%$ selectivity at $120^{\circ} \mathrm{C}$, whereas the calculated 6-AC-2-MN yields reaches $6.8 \%$ at $140{ }^{\circ} \mathrm{C}$ and $8.3 \%$ at $160^{\circ} \mathrm{C}$.

\section{Influence of mole ratios of 2-MN and $A A$}

Table 2 shows the acylation data for different mole ratios of 2-MN and AA. It can be observed that only $55.3 \% 2-\mathrm{MN}$ conversion can be obtained with an equal equivalent of AA applied. While increasing the molar ratio of 2-MN and AA up to $1: 1.5$, the conversion reaches $66.1 \%$ with a selectivity of $98.3 \%$. Further increasing of the amount of AA leads to the decrease of both conversion and selectivity. This indicates that excessive amount of AA might also increase the activity of deacylation and acetyl migration reactions. Accordingly, the favorable molar ratio of 2-MN and AA is 1:1.5 for the formation of 1-AC-2MN.

\section{Influence of catalyst amount on the acylation of 2- $M N$}

Different amounts of catalyst were applied at a mole ratio of 2-MN : AA equal to $1: 1.5$ at $120^{\circ} \mathrm{C}$ in $[\mathrm{BPy}] \mathrm{BF}_{4}$. In general, the higher the catalyst amount applied, the higher is the conversion of 2MN (Table 3). The highest conversion of $70.4 \%$ is achieved with $0.2 \mathrm{~mol} \%$ of the catalyst applied. The conversion is not significantly increased with further increase in catalyst amount. In contrast, the selectivity slightly decreases with the increase in catalyst amount. This is also not a surprise since a high catalytic amount may also accelerate the deacylation and rearrangement reactions.

Based on the experiments performed above, we can conclude that the $\mathrm{H}_{3} \mathrm{PW}_{12} \mathrm{O}_{40} /[\mathrm{BPy}] \mathrm{BF}_{4}$ catalytic system shows a good activity towards acylation of 2-MN, with the formation of 1-AC-2$\mathrm{MN}$ as the major product and 6-AC-2-MN as a byproduct. The optimal reaction conditions for the formation of 1-AC-2-MN are: n2-MN: $\mathrm{nAA}=1: 1.5$, with $0.2 \mathrm{~mol} \%$ of $\mathrm{H}_{3} \mathrm{PW}_{12} \mathrm{O}_{40}$ catalyst applied at $120^{\circ} \mathrm{C}$ for $6 \mathrm{~h}$ in $[\mathrm{BPy}] \mathrm{BF}_{4}$ solvent. 
Y. Guo et al.: Friedel-Crafts acylation of 2-methoxynaphthalene with acetic anhydride catalyzed by phosphotungstic...

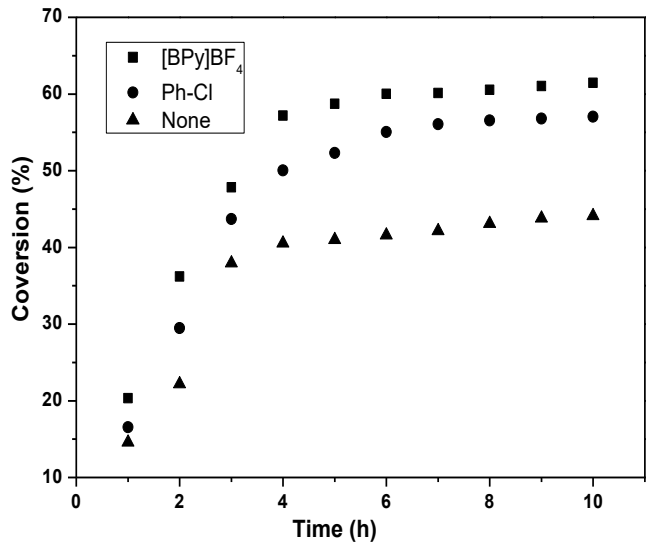

Fig. 1. Time-dependent conversion of $2-\mathrm{MN}$ in the presence of ionic liquid $[\mathrm{BPy}] \mathrm{BF}_{4}$, chlorobenzene or under solvent free conditions. Reaction conditions: 2-MN (3.16 g, $20 \mathrm{mmol})$, n2-MN:nAA =1:1.5, $\mathrm{H}_{3} \mathrm{PW}_{12} \mathrm{O}_{40}(0.06 \mathrm{~g}, 0.02 \mathrm{mmol})$, solvent $10 \mathrm{~mL}$ at $100{ }^{\circ} \mathrm{C}$

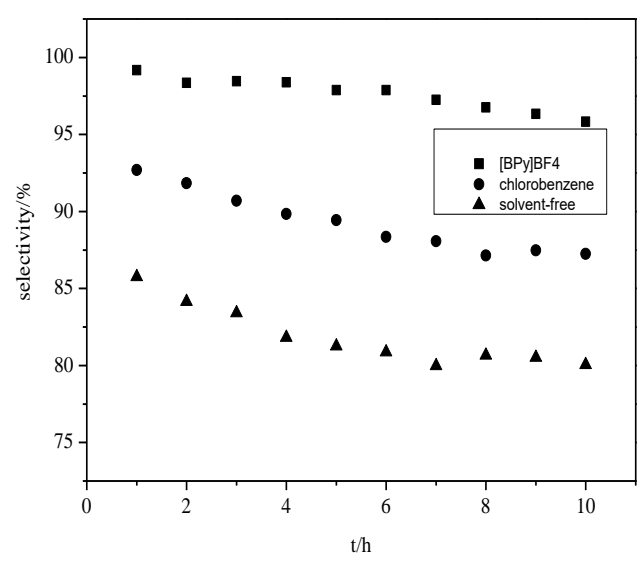

Fig. 2. Time-dependent selectivity towards 1-AC-2$\mathrm{MN}$ in the presence of ionic liquid $\left[\mathrm{BPy}^{\mathrm{B}} \mathrm{BF}_{4}\right.$, chlorobenzene or under solvent free conditions. Reaction conditions: 2-MN (3.16 g, $20 \mathrm{mmol})$, n2$\mathrm{MN}: \mathrm{nAA}=1: 1.5, \quad \mathrm{H}_{3} \mathrm{PW}_{12} \mathrm{O}_{40}(0.06 \mathrm{~g}, \quad 0.02 \mathrm{mmol})$, solvent $10 \mathrm{~mL}$ at $100^{\circ} \mathrm{C}$

Table 1. Influence of temperature on the acylation of 2-MN.

\begin{tabular}{|c|c|c|c|c|c|c|}
\hline \multirow{2}{*}{ Entry $^{\mathrm{a}}$} & \multirow{2}{*}{$\begin{array}{c}\text { Temperature } \\
\left({ }^{\circ} \mathrm{C}\right)\end{array}$} & \multirow{2}{*}{$\begin{array}{c}\text { Conversion } \\
(\%)\end{array}$} & \multicolumn{2}{|c|}{ Selectivity (\%) } & \multicolumn{2}{|c|}{ Yield (\%) } \\
\hline & & & 1-AC-2-MN & 6-AC-2-MN & 1-AC-2-MN & 6-AC-2-MN \\
\hline 1 & 60 & 30.6 & 99.9 & 0.3 & 31.2 & 0.2 \\
\hline 2 & 80 & 43.2 & 99.8 & 0.2 & 43.1 & 0.2 \\
\hline 3 & 100 & 60.1 & 98.9 & 0.1 & 60.4 & trace \\
\hline 4 & 120 & 66.1 & 98.3 & 0.9 & 64.7 & trace \\
\hline 5 & 140 & 56.6 & 84.4 & 12.8 & 48.2 & 6.8 \\
\hline 6 & 170 & 52.3 & 80.6 & 15.4 & 42.1 & 8.3 \\
\hline
\end{tabular}

${ }^{\mathrm{a}}$ Reaction conditions: 2-MN (3.16 g, $\left.20 \mathrm{mmol}\right), \mathrm{n} 2-\mathrm{MN}$ : $\mathrm{nAA}=1: 1.5, \mathrm{H}_{3} \mathrm{PW}_{12} \mathrm{O}_{40}(0.06 \mathrm{~g}, 0.02 \mathrm{mmol}),[\mathrm{BPy}] \mathrm{BF}_{4}(10$ $\mathrm{mL}$ ) for $6 \mathrm{~h}$.

Table 2. Influence of molar ratios between 2-MN and AA

\begin{tabular}{|c|c|c|c|c|c|c|}
\hline \multirow{2}{*}{ Entry $^{\mathrm{a}}$} & \multirow{2}{*}{$\begin{array}{c}\text { 2-MN: } \\
\text { AA }\end{array}$} & \multirow{2}{*}{ Conversion $(\%)$} & \multicolumn{2}{|c|}{ Selectivity (\%) } & \multicolumn{2}{|c|}{ Yield $(\%)$} \\
\hline & & & 1-AC-2-MN & 6-AC-2-MN & 1-AC-2-MN & 6-AC-2-MN \\
\hline 1 & $1: 1$ & 55.3 & 97.8 & 1.1 & 54.1 & 0.7 \\
\hline 2 & $1: 1.3$ & 60.6 & 97.3 & 1.8 & 59.2 & 0.9 \\
\hline 3 & $1: 1.5$ & 66.1 & 98.3 & 1.7 & 65.0 & 1.1 \\
\hline 4 & $1: 1.7$ & 60.6 & 87.2 & 11.7 & 53.2 & 7.3 \\
\hline 5 & $1: 2$ & 56.1 & 68.6 & 20.1 & 39.3 & 11.3 \\
\hline 6 & 1.2 .5 & 55.3 & 67.8 & 20.3 & 37.4 & 11.4 \\
\hline
\end{tabular}

\footnotetext{
${ }^{\mathrm{a}}$ Reaction conditions: 2-MN (20 mmol), $\mathrm{H}_{3} \mathrm{PW}_{12} \mathrm{O}_{40}(0.06 \mathrm{~g}, 0.02 \mathrm{mmol}),[\mathrm{BPy}] \mathrm{BF}_{4}(10 \mathrm{~mL})$ at $120^{\circ} \mathrm{C}$ for $6 \mathrm{~h}$.
} 
Y. Guo et al.: Friedel-Crafts acylation of 2-methoxynaphthalene with acetic anhydride catalyzed by phosphotungstic...

Table 3. Influence of catalyst amount on the acylation of 2-MN

\begin{tabular}{ccccc}
\hline Entry $^{\mathrm{a}}$ & $\begin{array}{c}\text { Catalyst amount } \\
(\text { mol \%) }\end{array}$ & $\begin{array}{c}\text { Conversion } \\
(\%)\end{array}$ & $\begin{array}{c}\text { Selectivity } \\
(\%)\end{array}$ & $\begin{array}{c}\text { Yield } \\
(\%)\end{array}$ \\
\hline 1 & 0.03 & 45.5 & 99.9 & 45.7 \\
2 & 0.06 & 52.4 & 99.9 & 52.1 \\
3 & 0.10 & 66.2 & 97.8 & 65.2 \\
4 & 0.20 & 70.4 & 96.4 & 67.4 \\
5 & 0.25 & 70.2 & 91.1 & 64.1 \\
$6^{\mathrm{b}}$ & 0.30 & 70.1 & 85.4 & 60.3 \\
\hline
\end{tabular}

${ }^{a}$ Reaction conditions: 2-MN (20 mmol), n2-MN: $\mathrm{nAA}=1: 1.5, \mathrm{H}_{3} \mathrm{PW}_{12} \mathrm{O}_{40}$ as catalyst, $[\mathrm{BPy}] \mathrm{BF}_{4}(10 \mathrm{~mL})$ at $120{ }^{\circ} \mathrm{C}$ for $6 \mathrm{~h}$; ${ }^{\mathrm{b}} \mathrm{The}$ reaction was performed at $140{ }^{\circ} \mathrm{C}$ for $10 \mathrm{~h}$.

\section{Recycling and reuse of catalyst and ionic liquid}

After the acylation reaction, the products and unreacted substrates were extracted by ethyl acetate. The resulting ionic liquid solution containing the catalyst $\mathrm{H}_{3} \mathrm{PW}_{12} \mathrm{O}_{40}$ was further dried at $80^{\circ} \mathrm{C}$ under vacuum. Then, the mixture was used directly for the next catalytic run; no additional catalyst was added to the system. Figure 3 shows the catalytic data of the recycled $\mathrm{H}_{3} \mathrm{PW}_{12} \mathrm{O}_{40} /[\mathrm{BPy}] \mathrm{BF}_{4}$ system for acylation of 2$\mathrm{MN}$. The data (Fig. 3) indicate that the catalytic system can be recovered and reused at least 6 runs without significant loss of activity, with the overall 2 -MN conversion higher than $60.2 \%$, indicating a good stability of the catalytic system. However, the conversion starts to decrease after 6 runs. It was observed that the color of the recycled $\mathrm{H}_{3} \mathrm{PW}_{12} \mathrm{O}_{40} /[\mathrm{BPy}] \mathrm{BF}_{4}$ solution gradually turned from colorless to brownish with the increase in recycling times, which indicates the decomposition of ionic liquid or catalyst.

\section{Acylation of other aromatic compounds}

In order to further evaluate the catalytic performance of $\mathrm{H}_{3} \mathrm{PW}_{12} \mathrm{O}_{40} /[\mathrm{BPy}] \mathrm{BF}_{4}$ system, the acylation of other aromatic compounds was also examined in our studies. The mono-substituted benzene derivatives including anisole, toluene and $p$-xylene were selected as substrates for acylation reactions in our studies. The catalytic data are summarized in Table 4.

Despite the catalytic system shows good conversion of 2-MN, it seems not active towards benzene ring-derived aromatic compounds. All the examined reactions result in only low to medium product yield. It is known that the aromaticity of naphthalene ring is weaker than that of the benzene ring, thus the electrophilic substitution of naphthalene derivatives is easier than that of benzene-derived aromatic compounds. Accordingly, 2-MN shows higher activity than anisole, toluene and $p$-xylene towards the acylation reactions. As to different functional group(s)substituted benzenes, since the electron-donating ability of methoxyl group is stronger than that of methyl group, anisole shows higher activity than toluene for acylations while in the case of $p$-xylene, the activity is lower than that of toluene. This might be due to the steric effect of the two methyl groups at para-positions, which makes the acylation hard to occur. Moreover, the electrophilic substitution is known to be more active at para-position than at ortho-position of the phenyl ring, which may be also responsible for the low activity of $p$-xylene.

\section{CONCLUSIONS}

The acylation of 2-MN was carried out for the first time with acetic anhydride in $[\mathrm{BPy}] \mathrm{BF}_{4}$ ionic liquid using phosphotungstic acid as catalyst, resulting in the formation of kinetically stable 1AC-2-MN as main product and thermodynamically stable 6-AC-2-MN as byproduct. A conversion of $70.4 \%$ with $96.4 \%$ of 1 -AC-2-MN selectivity can be obtained under the conditions of n2-MN:nAA $=1: 1.5,0.2 \mathrm{~mol} \% \mathrm{H}_{3} \mathrm{PW}_{12} \mathrm{O}_{40}$ catalyst applied at $120{ }^{\circ} \mathrm{C}$ for $6 \mathrm{~h}$ in $[\mathrm{BPy}] \mathrm{BF}_{4}$ solvent. The recycled ionic liquid and catalyst mixture can be reused at least 6 times without significant loss of activity, indicating a good stability of the $\mathrm{H}_{3} \mathrm{PW}_{12} \mathrm{O}_{40}$ l $[\mathrm{BPy}] \mathrm{BF}_{4}$ catalytic system. 
Y. Guo et al.: Friedel-Crafts acylation of 2-methoxynaphthalene with acetic anhydride catalyzed by phosphotungstic...

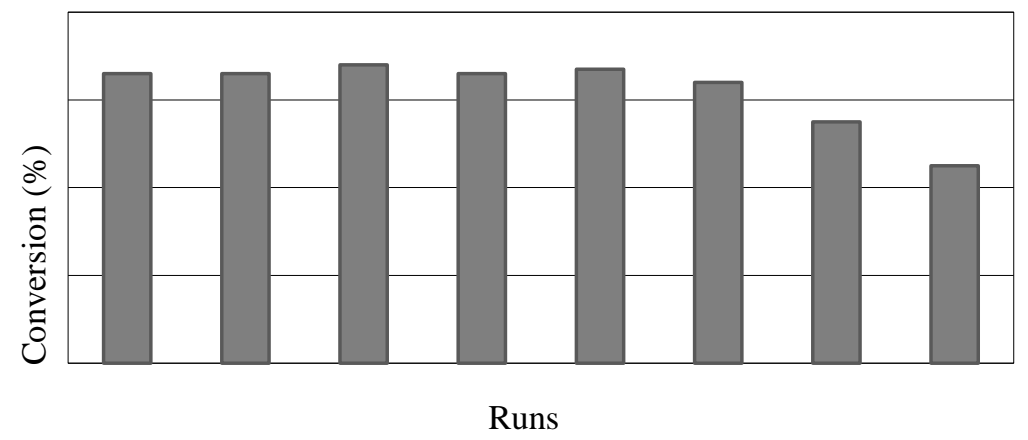

Fig. 3. Reuse of the catalytic system for acylation of 2-MN. Reaction conditions: 2-MN (3.16 g, $20 \mathrm{mmol})$, n2-MN: $\mathrm{nAA}=1: 1.5, \mathrm{H}_{3} \mathrm{PW}_{12} \mathrm{O}_{40}(0.06 \mathrm{~g}, 0.02 \mathrm{mmol}),[\mathrm{BPy}] \mathrm{BF}_{4}(10 \mathrm{~mL})$ at $120^{\circ} \mathrm{C}$ for $6 \mathrm{~h}$.

Table 4. Friedel-Crafts acylation of different aromatic compounds with AA

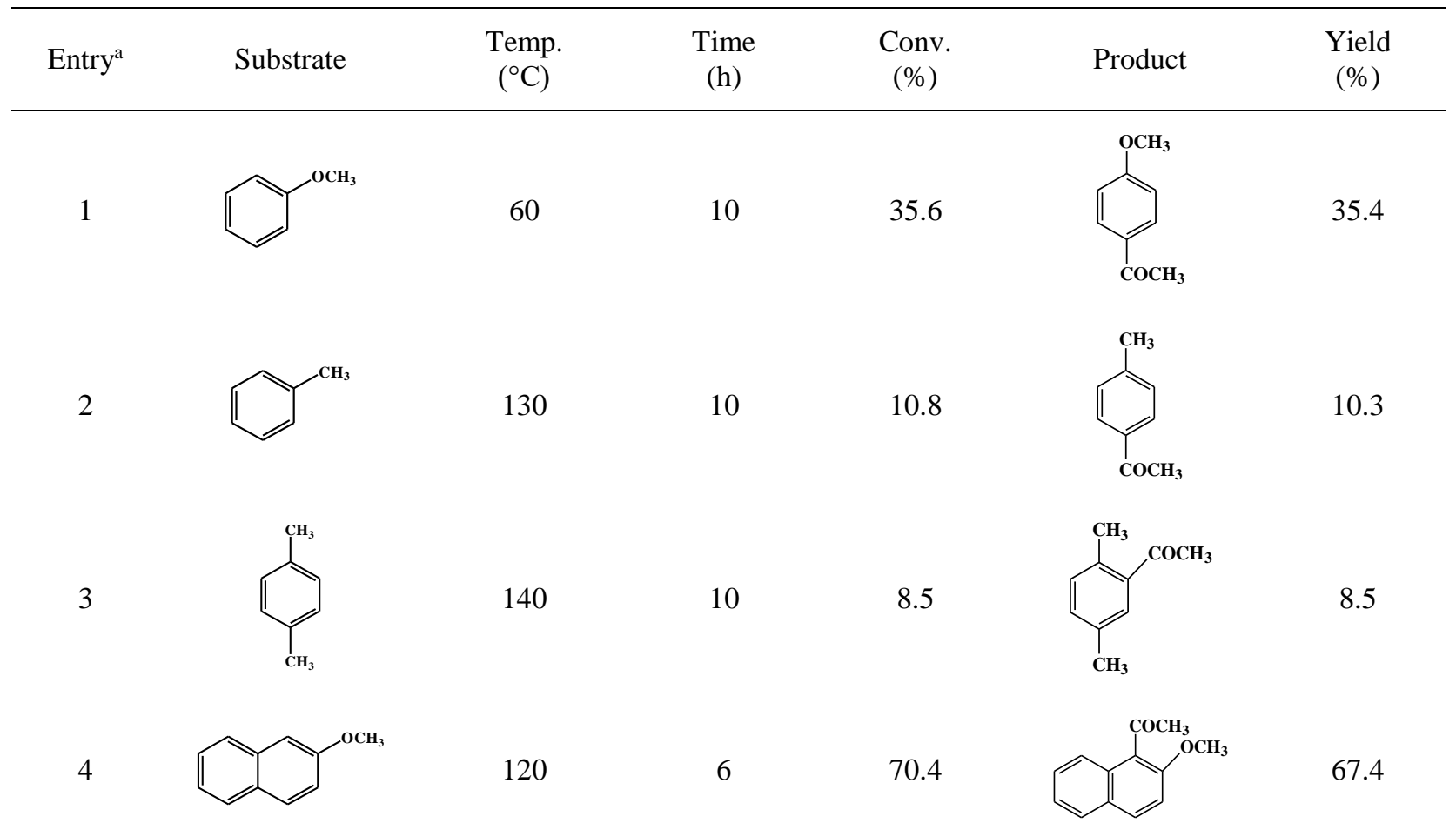

${ }^{\mathrm{a}}$ Reaction conditions: substrate $(20 \mathrm{mmol}), \mathrm{AA}(30 \mathrm{mmol}), \mathrm{H}_{3} \mathrm{PW}_{12} \mathrm{O}_{40}(0.12 \mathrm{~g}, 0.04 \mathrm{mmol}),[\mathrm{BPy}] \mathrm{BF} 4(10 \mathrm{~mL})$.

Acknowledgement: We thanks the National Science Foundation of China (21101085), Natural Science Foundation of Liaoning Province (2015020196, 20180540085), Fushun Science \& Technology Program (FSKJHT 201423), and Liaoning Excellent Talents Program in University (LJQ2012031) for the financial supports.

\section{REFERENCES}

1. H. G. Frank, J. W. Stadelhofer, Industrial aromatic chemistry, Chapter 5: Production and uses of benzene derivatives, Springer, Berlin, 1988, p. 137.

2. A. Baiker, H. U. Blaser, in: G. Ertl, H. Knözinger, J. Weitkamp (eds.), Handbook of Heterogeneous Catalysis, vol. 5, Wiley-VCH, Weinheim, 1997, p. 2422.

3. K. T. Wan, M. E. Davis. J. Catal., 152, 25 (1995).
4. M. E. Davis, Micropor. Mesopor. Mat., 4, 173 (1998)

5. S. Pivsa-Art, K. Okuro, M. Miura, S. Murata, M. Nomura, J. Chem. Soc. Perkin. Trans. 1, 1703 (1994).

6. P. J. Harrington, E. Lodewijk, Org. Process. Res. Dev., 1, 72 (1994).

7. R. A. Sheldon, H. van Bekkum, in: Fine Chemicals through heterogeneous Catalysis, R.A. Sheldon and H. van Bekkum (eds.), Wiley-VCH, Weinheim, 2001.

8. K. Tanabe, W. E. Hölderich, Appl. Catal. A-Gen., 181, 399 (1999).

9. A. Berreghis, P. Ayrault, E. Fromentin, M. Guisnet, Catal. Lett., 68, 121 (2000).

10. E. Fromentin, J M. Coustard, M. Guisnet, J. Catal., 190, 433 (2000).

11. E. Fromentin, J. Coustard, M. Guisnet, J. Mol. 
Y. Guo et al.: Friedel-Crafts acylation of 2-methoxynaphthalene with acetic anhydride catalyzed by phosphotungstic ... Catal. A-Chem., 159, 377 (2000).

12. H. Heinichen, W. Hölderich, J. Catal., 185, 408 (1999).

13. M. Casagrande, L. Storaro, M. Lenarda, R. Ganzerla, Appl. Catal. A-Gen., 201, 263 (2000).

14. P. Meric, A. Finiels, P. Moreau, J. Mol. Catal. AChem., 189, 251 (2002).

15. G. Harvey, G. Mader, Collect. Czech. Chem. Commun., 57, 862 (1992).

16. P. Andy, J. Garcia-Martinez, G. Lee, H. Gonzalez, C. Jones, M. Davis, J. Catal., 192, 215 (2000).

17. D. Das, S. Cheng, Appl. Catal. A-Gen., 201, 159 (2000).

18. S. Kim, K Lee, J. Lee, Y. Kim, K. Yoon. J. Mol. Catal. A-Chem., 152, 33 (2000).

19. L. Červený, K. Mikulcová, J. Čejka, Appl. Catal. AGen., 223, 65 (2002).

20. P. Moreau, A. Finiels, P. Meric, F. Fajula, Catal. Lett., 85, 199 (2003).

21. B. Yuan, Z. Li, Y. Liu, S. Zhang, J. Mol. Catal. AChem., 280, 210 (2008).

22. E. Gunnewegh, S. Gopie, H. Bekkum, J. Mol. Catal. A. Chem., 106, 151 (1996).

23. M. Selvaraj, K. Lee, K. Yoo, T. Lee, Micropor. Mesopor. Mat., 81, 343 (2005).

24. P. Botella, A. Corma, M. Navarro, F. Rey, G. Sastre, J. Catal., 217, 406 (2003).

25. P. Botella, A. Corma, G. Sastre, J. Catal., 197, 81 (2001).

26. P. Chen, W. Wang, Y. Zhai, J. Porous Mat., 21, 441 (2014).

27. H. Schuster, W. Hölderich, Appl. Catal. A-Gen., 350, 1 (2008).

28. A. Pârvulescu, B. Gagea, V. Pârvulescu, D. Vos, P. Jacobs, Appl. Catal. A-Gen., 306159 (2006).

29. D. Katsoulis, Chem. Rev., 98, 359 (1998).

30. A. Dolbecq, E. Dumas, C. Mayer, P. Mialane, Chem. Rev., 110, 6009 (2010).

31. K. Kamata, K. Yonehara, Y. Nakagawa, K. Uehara, N. Mizuno, Nature Chem., 2, 478 (2010).

32. C. Isabel, J. Gamelas, M. Balula, J. Mol. Catal. AChem., 262, 41 (2007).

33. S. Zhao, J. Xu, M. Wei, Y. Song, Green Chem., 13, 384 (2011).

34. J. Sousa, I. Santos, Catal. Commun., 12, 459 (2011).

35. N. Mizuno, K. Yamaguchi, K. Kamata, Catal. Surv. Asia, 15, 68 (2011).

36. P. Liu, C. Wang, C. Li, J. Catal., 262, 159 (2009).

37. Y. Wang, J. Wang. D. Zhu, M. Zhang, Green Chem., 13, 1636 (2011).

38. L. Ghamati, O. Walter, U. Amold, Eur. J. Inorg. Chem., 17, 2756 (2011).

39. Y. Yamamoto, S. Hatanaka, K. Tsuji, Appl. Catal. A-Gen., 344, 55 (2008).

40. E. Caliman, A. José, C. Sílvia, Micropor. Mesopor. Mat., 132, 103 (2010).

41. L. Wee, S. Bajpe, N. Janssens, Chem. Comm., 46 8186 (2010).

42. Y. Leng, J. Wang, D. Zhu, Angew. Chem. Int. Ed., 48168 (2009).

43. A. Alsalme, E. Kozhevnikova, I. Kozhevnikov, Appl. Catal. A-Gen., 349, 170 (2008).

44. G. Sunita, B. Devassy, A. Vinu, Catal. Comm., 9 696 (2008).

45. C. Kumar, P. Prasad, N. Lingaiah, Appl. Catal. AGen., 384, 101 (2010).

46. J. Satam, R. Jayaram, Catal. Comm., 9, 1937 (2008).

47. C. Kumar, K. Rao, P. Prasad, N. Lingaiah, J. Mol. Catal. A. Chem., 337, 17 (2011).

48. G. Kamalakar, K. Komura, Y. Kubota, Y. Sugi, J. Chem. Technol. Biot., 81, 981 (2006).

49. G. Sartori, R. Maggi, Chem. Rev., 106, 1077 (2006).

50. I. Kozhevnikov, Chem. Rev., 98, 171 (1998).

51. I. Kozhevnikov, Appl. Catal. A-Gen., 256, 3 (2003).

52. C. Castro, A. Corma, J. Primo, J. Mol. Catal. AChem., 177, 273 (2002).

53. J. Kaur, I. Kozhevnikov, Chem. Commun., 21, 2508 (2002).

54. J. Kaur, K. Griffin, B. Harrison, I. Kozhevnikov, J. Catal., 208, 448 (2002).

55. J. Huddleston, A. Visser, W. Reichert, H. Willauer, G. Broker, R. Rogers, Green Chem., 3, 156 (2001).

56. E. G. Derouane, G. Crehan, C. J. Dillon, D. Bethell, H. He, S. B. Derouane-Abd Hamid, J. Catal., 194, 410 (2000).

57. J. Boon, J. Levisky, J. Pflug, J. Wilkes, J. Org. Chem., 51, 480 (1986).

58. J. K. Surette, L. Green, R. D. Singer, Chem. Commun., 24, 2753 (1996).

59. G. D. Luer, D. E. Bartak, J. Org. Chem., 47, 1238 (1982).

60. D. S. Newman, R. E. Winans, R. L. McBeth, J. Electrochem. Soc., 131, 1079 (1984).

61. Y. Chauvin, A. Hirschauer, H. Olivier, J. Mol. Catal. A-Chem., 92, 155, (1994).

62. V. R Koch, L. L. Miller, R. A. Osteryoung, J. Am. Chem. Soc., 98, 5277 (1976).

63. T. Welton, Chem. Rev., 99, 2071 (1999).

64. S, Park, R. J. Kazlauskas, J. Org. Chem., 66, 8395 (2001).

65. J. Z. Yang, X. M .Lu, J. S .Gui, W. G. Xu, H. W. Li, J. Chem. Thermodyn., 37, 1250 (2005).

66. V. Singh, S. Kaur, V. Sapehiyia, J. Singh, G. L. Kad, Catal. Commun., 6, 57 (2005).

67. F. Durap, M. Aydemir, A. Baysal, D. Elma, B. Ak, Y. Turgut, Inorg. Chim. Acta, 411, 77 (2014).

68. Q. G. Deng, Z. L. Qin, Y. Yang, W. M. Song, J. Chem. Eng., 23, 384 (2015).

69. R. Ballini, L. Barboni, G. Bosica, J. Org. Chem., 65, 6261 (2000).

70. R. Srivastava, Catal. Lett., 139, 17 (2010). 